\title{
Self-collected versus clinician-collected cervical samples for the detection of HPV infections by 14-type DNA and 7-type mRNA tests
}

\author{
C. E. Aranda Flores', G. Gomez Gutierrez ${ }^{2}$, J. M. Ortiz Leon², D. Cruz Rodriguez ${ }^{3}$ and S. W. Sørbye ${ }^{4^{*}}$
}

\begin{abstract}
Background: HPV self-sampling has been widely supported by the scientific community following a strong body of literature on the subject. Self-sampling is important in cervical cancer screening as it has been shown to improve participation. It is well documented that HPV-testing has proven superior to cytology with regards to sensitivity in detection of CIN and cancer. The value of self-collected samples is reliant on the quality of the molecular testing performed, as well as the patients' preference in sampling procedure and compliance to follow up on positive test results. Due to the incompatibility of self-samples and cytology, triage of HPV-DNA positives by testing for molecular biomarkers is highly warranted.
\end{abstract}

Methods: Our objective was to compare the detection rate of genital Human Papillomavirus (HPV) infection in selfand clinician-collected samples by a 14-type HPV-DNA test and a 7-type mRNA E6/E7 test.

Results: Five hundred five women were recruited. Each study participant had two sample collection procedures performed upon the same visit, alternating order in execution of the self-collection or the clinician-taken procedure first or second, 1010 samples in total. HPV-DNA prevalence was $22.8 \%$ in self-collected versus $19.2 \%$ in cliniciancollected samples $(P=0.19)$. Overexpression of mRNA E6/E7 from $7 \mathrm{HPV}$ types was 7.1 and $6.3 \%$, respectively $(P=$ $0.71)$. The difference between HPV-DNA and HPV-mRNA positivity rates were statistically significant in both selfcollected $(22.8 \%$ versus $7.1 \%, P<0.001)$ and clinician-collected samples $(19.2 \%$ versus $6.3 \%, P<0.001)$. Overall agreement between the two collection methods was fair, with a concordance rate of 78.2\% (390/505), $k=0.34$ (95\% Cl: $0.25-0.44), P<0.001$, for the HPV-DNA test and $92.5 \%$ (467/505), $\mathrm{k}=0.40(95 \% \mathrm{Cl}, 0.25-0.56), P<0.001$, for the mRNA test, respectively. $96.8 \%$ of the participants reported they felt confident carrying out the self-collection themselves, and $88.8 \%$ reported no discomfort at all performing the procedure.

Conclusions: This comparative study of two sampling methods reports fair agreement of HPV positivity rates between the self-collected and clinician-collected specimens using Abbott hrHPV and PreTect HPV-Proofer'7 tests. Only one third of HPV-DNA positive women had overexpression of mRNA E6/E7.

Trial registration: ISRCTN77337300.

\footnotetext{
* Correspondence: sveinung.sorbye@unn.no

${ }^{4}$ Department of Clinical Pathology, University Hospital of North Norway, Tromsø, Norway

Full list of author information is available at the end of the article
}

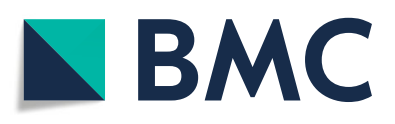

(- The Author(s). 2021 Open Access This article is licensed under a Creative Commons Attribution 4.0 International License, which permits use, sharing, adaptation, distribution and reproduction in any medium or format, as long as you give appropriate credit to the original author(s) and the source, provide a link to the Creative Commons licence, and indicate if changes were made. The images or other third party material in this article are included in the article's Creative Commons licence, unless indicated otherwise in a credit line to the material. If material is not included in the article's Creative Commons licence and your intended use is not permitted by statutory regulation or exceeds the permitted use, you will need to obtain permission directly from the copyright holder. To view a copy of this licence, visit http://creativecommons.org/licenses/by/4.0/ The Creative Commons Public Domain Dedication waiver (http://creativecommons.org/publicdomain/zero/1.0/) applies to the data made available in this article, unless otherwise stated in a credit line to the data. 
Keywords: Cervical cancer, Cervicovaginal self-sampling, Hr-HPV DNA, Cervical tumor markers, E6/E7 mRNA, XytoTest

\section{Background}

Cervical cancer is a major public health problem, and the second most common cancer in women living in less developed regions with an estimated 570,000 new cases in 2018. According to the World Health Organization, approximately 311,000 women died from cervical cancer in 2018: more than $85 \%$ of these deaths occurring in low- and middle-income countries [1]. In Mexico, it is the third most common malignancy among women [2]. Infection by high-risk Human Papillomavirus (hr-HPV) of the cervicovaginal tract is known to be the major cause of cervical cancer [3]. HPV-detection in cliniciancollected cervical samples has proven its superiority to cervical cytology in primary screening for prevention of cervical cancer $[4,5]$ and we are facing a paradigm shift towards molecular HPV-testing on a global perspective. Different national guidelines and follow-up algorithms are suggested, to maximize screening benefits. The shift will increase program sensitivity, however accurate triage of test positives is needed since Human Papillomavirus infection is the most common sexually transmitted viral disease in adult women. It is estimated that the vast majority of sexually active women will be exposed to the virus at some point in their lives [6]. Every programs success relies on a high coverage rate among the target population. Selfcollection of cervical samples is reported to be highly acceptable and preferred by most women, being a promising approach to enhance women's participation in regular screening for cervical cancer prevention [7]. It offers significant benefits over conventional sampling in terms of cost, coverage and convenience for patients. Self-sampling reaches high-risk groups who currently have limited access to national health system screening for personal and practical reasons [8]. Numerous studies comparing selfcollected and clinician-collected samples for HPV detection show good concordance when clinically validated PCR-based methods are used $[9,10]$. In a meta-analysis by Arbyn et al., self-sampled HPV tests based on PCR for the detection of CIN2+ were shown not to have statistically different sensitivity or specificity compared with cliniciansampled tests [11].

Currently, most guidelines recommend cytology in triage of HPV-DNA positives. As PAP reflex testing is not applicable on self-collected material, a new cliniciancollected sample is required for the purpose of triage, hereby suffering increased risk of loss to follow up; based on the nature of non-attenders. An alternative to cytology in triage could be detection of molecular biomarkers; being compatible on self-sampled material [12].
Literature describes effects caused by device and specimen processing in terms of various concentration and quality of cellular material that possibly impair test performance $[11,13]$ while few studies have evaluated the feasibility to collect sufficient material for both primary HPV-testing with direct molecular triage.

This study was conducted to compare the performance of self-collected samples by using a self-sampling device (XytoTest, Mel-Mont Medical, US) versus clinician-collected samples by using the professional-use device (Cervex-Brush, Rovers Medical Devices, Oss, the Netherlands) in combination with a 14-type HPV-DNA and 7-type mRNA E6/E7 test as the primary outcome.

Patient-reported acceptability of the self-collected samples method was the only secondary outcome.

\section{Methods}

The study was approved by the institutional ethics review board $(\mathrm{CI} / 243 / 18)$ at Eduardo Liceaga, Mexico General Hospital, Mexico City, before commencing.

Trial registration: ISRCTN, ISRCTN77337300. Registered 15 December 2020 - Retrospectively registered, http://www.isrctn.com/ISRCTN77337300

During the period August 2018 to April 2019, study participants were recruited among women attending cervical cancer screening and among health professionals working at the Oncology clinic of Eduardo Liceaga, Mexico General Hospital, Mexico City. Eligible were sexually active women aged 30-65 that responded positively to the invitation and had no history of medical or surgical treatment (radiotherapy, chemotherapy, hysterectomy, cone biopsy) for cervical cancer. Excluded were pregnant and breastfeeding women, those who had had sexual activity within $24 \mathrm{~h}$ before to the collecting samples procedure, and those who chose not to sign the informed consent. Prior to enrollment, the purpose and nature of the study were explained to each participant to obtain their written consent. The two sampling procedures were performed upon the same day, in alternating order for each participant upon arrival. Since the study was conducted at the clinic for cervical screening, clinicians' additional training was unnecessary to collect the reference sample. For the self-sampling device, the manufacturer's written and illustrated instructions for use in Spanish were provided to all participants. The procedure was performed in a separate room for the women's discretion without assistance by health staff. Finally, after the samples were collected, the participant completed a questionnaire about her experience during the self- 
collection procedure. Respondents scored items on an 8point Likert scale, ranging from 1 ("no discomfort") to 8 (unbearable discomfort"). All women were informed to discuss their test results upon completion with a healthcare professional to decide on further follow-up. Patient sensitive information was anonymized by a 6-digit code and registered using Microsoft Excel 16.16.23 (2006152016). Only study responsible staff at the hospital had access to the registered information.

\section{Self-collected samples}

The participants of this study performed self-collection of cervicovaginal material using the XytoTest medical device (Mel-Mont Medical, USA), an ergonomically designed device to be inserted into the vagina, with a diameter less than $8 \mathrm{~mm}$ and a length of $14 \mathrm{~cm}$ [14]. The cell collection area is made of USP medical grade IV elastomer, allowing for immediate collection of cells when inserted into the vaginal canal. A chemical release of cells occurs when resuspending the device in a methanol-based preservative [14]. The instruction leaflet (attached as supplementary file; S1) guides women to collect the sample from a gynecological position; laying on their back with their legs bent, spread the labia with one hand and carefully insert the device into the vagina with the other until the lower flap of the device contacts the skin and slowly rotate it $360^{\circ}$ in the same direction three times before retracting the device and placing it in the container provided. The sample was given to the clinician, who thoroughly washed the device in $5 \mathrm{ml}$ of PreservCyt Solution (Hologic, UK) for at least $2 \mathrm{~min}$ to release cell material for subsequent HPV-testing.

\section{Clinician-collected samples}

A clinician collected the sample by using the CervexBrush $^{\oplus}$ (Rovers Medical Devices, Oss, the Netherlands), which is among the most widely used method for cervical cancer screening, commonly used as a reference method for validation of new devices [15]. After sampling according to the manufacturer's instructions, the brush was immediately rinsed in $5 \mathrm{ml}$ of PreservCyt Solution (Hologic, UK) for subsequent HPV-testing. Cellularity was calculated for $19.2 \%(97 / 505)$ of the paired samples collected by performing a manual cell count using the Bürker Chamber [16].

\section{HPV-DNA test}

The Abbott RealTime HR HPV test (Abbott, Wiesbaden, Germany) is an automated, qualitative multiplex assay based on real-time polymerase chain reaction (PCR) intended to detect 14 high-risk HPV genotypes $(16,18$, $31,33,35,39,45,51,52,56,58,59,66,68)$ and to partially genotype 16,18 from the other 12 high risk genotypes. Human Beta-globin is detected as an internal control. The test has been clinically validated according to international consensus guidelines and proved to also be accurate for self-collected samples [17, 18]. All samples were tested using the standard procedure and interpreted according to the manufacturer's threshold for positivity $\mathrm{CT}<32.0$. Any invalid sample with respect to Beta-globin was retested and excluded from the study population if repeatedly invalid.

\section{HPV mRNA E6/E7 test}

PreTect HPV-Proofer'7 (Pre'Tect AS, Klokkarstua, Norway) is a diagnostic kit for the qualitative detection and direct typing of E6/E7 mRNA from HPV 16, 18, 31, 33, 45, 52 and, 58. The kit contains an intrinsic sample control (ISC) targeting a human housekeeping gene to assess specimen quality and reveal possible factors that may inhibit amplification. The kit utilizes real-time NASBA technology, an enzymatic one-step amplification process able to amplify RNA under isothermal conditions at $41{ }^{\circ} \mathrm{C}$ [19]. Several publications describe PreTect HPV mRNA assays' clinical performance, holding high specificity in low-grade cytology triage [19-21]. All samples were tested and interpreted according to the manufacturer's standard procedure. Any invalid sample with negative mRNA intrinsic sample control was retested and excluded from the study population if repeatedly invalid.

\section{Statistical analysis}

The sample size was estimated considering a two-tailed hypothesis, with a 95\% confidence interval, a statistical power of $80 \%$, and an effect size (Cohen's d) of 0.12555 . With these characteristics, the estimated sample size required was 500 study participants, calculated using the software GPower 3.1.9.2. Microsoft Excel 2016 (Microsoft Corp., Redmond, WA) and IBM SPSS Statistics software package version 21 (IBM, Armonk, NY, USA) were used for data collection and evaluation. Cohen's Kappa coefficients were calculated to evaluate the agreement between the two sampling methods regarding hr-HPV results, applying the most commonly used scale to express the strength of the agreement as follows: 0.00$0.20,0.21-0.40,0.41-0.60,0.61-0.80$ and $\geq 0.81$ indicated slight, fair, moderate, substantial, and almost perfect, respectively. The Wilcoxon signed -rank test was applied to evaluate the differences between the two sampling methods. A statistically significant difference was defined as a $5 \%$ chance of a type I error $(\alpha \leq 0.05)$. For comparison of the presence of HPV-16, HPV-18, and 12 other hr-HPV genotypes between the two samples, the following terminology was used: concordant or discordant. A concordant result was determined if results from all three channels $(16,18$, and pool) showed at least one 
identical genotype in both samples, where discordance represented no similarities in genotypes at all.

\section{Results}

\section{Participant characteristics}

Overall, a total of 505 women participated in the study, everyone within the inclusion criteria. $65.5 \%$ of the participants were recruited among women attending the general screening program at the clinic, and $33.5 \%$ were recruited among the health professionals working at the Mexico General Hospital. The inclusion of health professionals was partially to learn whether the level of education might affect the quality of the sample evaluated by cellularity and sample integrity if the instructions for self-collection was not sufficiently clearly described as health professionals presumably would have a better understanding of sample taking in general. In total 1010 samples were collected equally distributed between selfcollected samples, and clinician collected specimens. All the collected samples by the two procedures were valid for processing. The mean age of the participants was $43.8 \pm 8.1$ years (median 44 , IQR 13 , range; $30-63$ ). Just over two-thirds of the women $(69.7 \%)$ reported they were older than 18 years when they first had sexual intercourse, and less than a third (30.3\%) were under the age of 18 (Table 1 ).

\section{Questionnaire}

Each of the four questions' response rate in the questionnaire was high, ranging between 99.0-99.2\%. Regarding women's acceptability of the self-sampling procedure, $88.8 \%$ reported no discomfort at all, $94.0 \%$ found no difficulty performing the self-sampling procedure, $96.6 \%$ agreed they would perform self-sampling again, and $96.8 \%$ said they felt confident carrying out the procedure themselves (Table 2).

\section{Hr-HPV prevalence}

The prevalence of hr-HPV-DNA varied from $22.8 \%$ (115/505; 95\% CI: $19.2-26.7)$ to $19.2 \%$ (97/505; 95\% CI: 15.9-22.9) among the self-collected and clinician-

Table 1 Characteristics of study population, $n=505$

\begin{tabular}{lll}
\hline Age (years) & & \\
Mean \pm SD & 43.8 & \pm 8.1 \\
Median \pm IQR & 44 & \pm 13 \\
Recruitment source & $\mathrm{n}$ & $(\%)$ \\
Health professionals & 169 & $(33.5)$ \\
Women attending screening & 336 & $(66.5)$ \\
Age at first sexual intercourse & & \\
$<18$ years & 153 & $(30.3)$ \\
$>18$ years & 352 & $(69.7)$ \\
\hline
\end{tabular}

Table 2 Questionnaire Responses (acceptability of selfcollection, $n=505$ )

\begin{tabular}{|c|c|c|}
\hline & $(n)^{a}$ & (\%) \\
\hline \multicolumn{3}{|c|}{ Level of discomfort } \\
\hline 1 & 445 & 88.8 \\
\hline 2 & 32 & 6.4 \\
\hline 3 & 10 & 2.0 \\
\hline 4 & 7 & 1.4 \\
\hline 5 & 1 & 0.2 \\
\hline 6 & 3 & 0.6 \\
\hline 7 & 2 & 0.4 \\
\hline 8 & 1 & 0.2 \\
\hline (Total responses) & 501 & 99.2 \\
\hline \multicolumn{3}{|c|}{ Level of difficulty } \\
\hline 1 & 471 & 94.0 \\
\hline 2 & 21 & 4.2 \\
\hline 3 & 4 & 0.8 \\
\hline 4 & 1 & 0.2 \\
\hline 5 & 1 & 0.2 \\
\hline 6 & 1 & 0.2 \\
\hline 7 & 1 & 0.2 \\
\hline 8 & 1 & 0.2 \\
\hline (Total responses) & 501 & 99.2 \\
\hline \multicolumn{3}{|c|}{ Would you perform self-sampling again? } \\
\hline Yes & 483 & 96.6 \\
\hline No & 17 & 3.4 \\
\hline (Total responses) & 500 & 99.0 \\
\hline \multicolumn{3}{|c|}{ Do you feel confident taking the sample? } \\
\hline Yes & 484 & 96.8 \\
\hline No & 16 & 3.2 \\
\hline (Total responses) & 500 & 99.0 \\
\hline
\end{tabular}

$a_{n}$ number of responses obtained

collected samples $(P=0.19)$, whilst the positivity rate for HPV mRNA E6/E7 was about one third; 7.1\% (36/505; 95\% CI: 5.0-9.7) versus 6.3\%, (32/505; 95\% CI: 4.4-8.8) respectively $(P=0.71)$.

The Wilcoxon test showed no statistically significant differences between the two sample-collection methods used prior to analysis by DNA and mRNA assays $(P>$ 0.05). Mostly non-HPV16/18 genotypes were detected. The vast majority of the infections identified in selfcollected samples were single (85.2\%) and multiple infections were found in 17 specimens (14.8\%) in line with 84.5 and $15.5 \%$ among clinician-collected samples (Table 3). The analysis of HPV genotype infections was restricted to count each infection only once and results 
Table 3 Partial hr-HPV genotyping results presented hierarchically by oncogenicity for clinician-collected (CC) and self-collected (SC) samples

\begin{tabular}{|c|c|c|c|c|}
\hline & \multicolumn{2}{|c|}{ 14-type DNA test } & \multicolumn{2}{|c|}{ 7-type mRNA test } \\
\hline & $\overline{C C}$ & SC & $\overline{C C}$ & SC \\
\hline & n (\%) & n (\%) & n (\%) & n (\%) \\
\hline \multicolumn{5}{|l|}{$\mathrm{N}=505$ included cases } \\
\hline HPV 16 & $15(3.0)$ & $16(3.2)$ & $7(1.4)$ & $9(1.8)$ \\
\hline HPV 18 (non 16) & $6(1.2)$ & $8(1.6)$ & $4(0.8)$ & $5(1.0)$ \\
\hline HPV other (non 16/18) & $76(15.0)$ & $91(18.0)$ & $21(4.2)$ & $22(4.4)$ \\
\hline Any hr-HPV & $97(19.2)$ & $115(22.8)$ & $32(6.3)$ & $36(7.1)$ \\
\hline \multicolumn{5}{|l|}{$\mathrm{N}=$ Any positive $\mathrm{hr}-\mathrm{HPV}$} \\
\hline Any multiple infections & $15(15.5)$ & $17(14.8)$ & $3(9.4)$ & $7(19.4)$ \\
\hline Any single infections & $82(84.5)$ & $98(85.2)$ & $29(90.6)$ & $29(80.6)$ \\
\hline
\end{tabular}

for both HPV-DNA and mRNA are shown hierarchically based on the established oncogenicity for cervical cancer. For self-collected samples tested by Abbott hr-HPV; a total of 16 out of 505 samples (3.2\%) showed single or multiple infections with genotype HPV-16; 8 samples (1.6\%) showed single or multiple infections with HPV-18 excluding any co-infections with HPV-16. A further 91 samples (18.0\%) showed single (or multiple) infections with non-16/18-HPV genotypes. For clinician-collected samples the results were 15/505 (3.0\%), $6(1.2 \%)$ and 76 (15.0\%), respectively (Table 3$)$. To have comparable statistics, the HPV mRNA genotype results were presented in the same way, HPV mRNA-16 (single and multiple), HPV mRNA-18 (non16), and HPV mRNA-31, 33, 45, 52, 58 positive (non16/18) samples (Table 3). Overall agreement between the two collection methods was fair, with a concordance rate at $78.2 \%(395 / 505), \mathrm{k}=0.34$ (95\% CI: $0.25-0.44), P<0.001$, for the HPV-DNA test and 92.5\% (467/505), $\mathrm{k}=0.40$ (95\% CI: 0.25-0.56), $P<$ 0.001, for the HPV mRNA test, respectively. In women with at least one positive HPV-test, the agreement was $31.7 \%(51 / 161)$ for the HPV-DNA test and 28.3\% (15/ 53) for the HPV mRNA test. Kappa for the mRNA test in the 161 women with at least one positive HPV DNA test was 0.30 (95\% CI: $0.12-0.48), P<0.001$ (Table 4).

A total of 115 women (22.8\%) had discordant HPVDNA results. In 46 cases, the women were cliniciancollected sample HPV-positive/self-collected sample HPV-negative. Among these, 24 had the cliniciancollected sample taken first and 22 women the selfsampling first in order. Sixty-four women were cliniciancollected sample HPV-negative/self-collected sample HPV-positive; among those of whom 27 had their first sample by their clinician versus 37 women self-sampling first. Five women were detected as hr-HPV positive in both samples collected, with no similarities in genotypes. Regardless of order of the method used, no significant differences in the agreement rates for self-collected, and clinician-collected sampling techniques were observed, $P=0.63$ for the HPV-DNA test and $P=0.23$ for HPV mRNA test, respectively (Table 5 ).

\section{Cellularity}

All 505 paired samples obtained valid results for the two subsequent HPV amplification tests done, hence no exclusions were made due to low cellularity. The manual cell count using Bürker chamber was done for a random subset of paired samples to evaluate the number of cells collected by each sampling method, 97 pairs in total. Forty-seven of the self-collected samples were done by health professionals, 50 self-collected by women attending screening. The average number of cells per milliliter was calculated following standard protocol and descriptive statistics are presented in (Table 6). The selfsampled aliquot contained about 3 times more cells compared to clinician taken aliquot; 1.87 million cells/ $\mathrm{ml}$ versus 0.63 million cells $/ \mathrm{ml}$, respectively. The

Table 4 Agreement of self- and clinician-collected samples by HPV assay

\begin{tabular}{|c|c|c|c|c|c|c|c|c|}
\hline & \multirow[b]{3}{*}{ Self-collected } & \multicolumn{3}{|c|}{ Clinician-collected samples } & \multirow{2}{*}{\multicolumn{2}{|c|}{ Cohens kappa }} & \multirow{2}{*}{\multicolumn{2}{|c|}{ Agreement }} \\
\hline & & \multirow{2}{*}{$\begin{array}{l}\text { HPV positive } \\
\text { n (\%) }\end{array}$} & \multirow{2}{*}{$\begin{array}{l}\text { HPV negative } \\
\text { n (\%) }\end{array}$} & \multirow{2}{*}{$\begin{array}{l}\text { Total } \\
\text { n (\%) }\end{array}$} & & & & \\
\hline & & & & & кb & $(95 \% \mathrm{Cl})$ & $\%$ & $(95 \% \mathrm{Cl})$ \\
\hline 14-type & HPV positive ${ }^{a}$ & $51(10.1)$ & $64(12.7)$ & $115(22.8)$ & & & & \\
\hline DNA & HPV negative & $46(9.1)$ & $344(68.1)$ & $390(77.2)$ & & & $78.2^{c}$ & $(74.6-81.8)$ \\
\hline assay & Total & $97(19.2)$ & $408(80.8)$ & $505(100.0)$ & $0.34^{\mathrm{e}}$ & $(0.25-0.44)$ & $31.7^{\mathrm{d}}$ & $(24.7-39.5)$ \\
\hline 7-type & HPV positive ${ }^{b}$ & $15(3.0)$ & $21(4.2)$ & $36(7.1)$ & & & & \\
\hline mRNA & HPV negative & $17(3.4)$ & $452(89.5)$ & $469(92.9)$ & $0.40^{\mathrm{e}}$ & $(0.25-0.56)$ & $92.5^{c}$ & $(90.2-94.8)$ \\
\hline assay & Total & $32(6.3)$ & $473(93.7)$ & $505(100.0)$ & $0.30^{f}$ & $(0.12-0.48)$ & $28.3^{d}$ & $(17.2-42.3)$ \\
\hline
\end{tabular}

a $(16,18,31,33,35,39,45,51,52,56,58,59,66,68)$

b $(16,18,31,33,45,52,58)$

c Agreement overall

d Agreement in women with at least one positive HPV test

e Cohen kappa overall $(N=505)$

${ }^{f}$ Cohen kappa in women with at least one positive HPV DNA test $(N=161)$ 
Table 5 Paired agreement and order of procedure for Clinician-collected (CC) and Self-collected (SC) samples

\begin{tabular}{|c|c|c|c|c|c|c|}
\hline \multirow[b]{2}{*}{ Paired Agreement } & \multicolumn{3}{|c|}{ 14-type DNA ${ }^{\text {a }}$} & \multicolumn{3}{|c|}{ 7-type mRNA ${ }^{b}$} \\
\hline & $n$ & CC first & SC first & $\mathrm{n}$ & CC first & SC first \\
\hline Concordant & 390 & 195 & 195 & 466 & 225 & 241 \\
\hline Only Clinician-collected sample positive & 46 & 24 & 22 & 17 & 10 & 7 \\
\hline Only Self-collected sample positive & 64 & 27 & 37 & 21 & 14 & 7 \\
\hline Both samples positive, Different genotypes & 5 & 3 & 2 & 1 & 0 & 1 \\
\hline Total & 505 & 249 & 256 & 505 & 249 & 256 \\
\hline
\end{tabular}

${ }^{\mathrm{a}} p=0.63$, Pearson's Chi-squared test ${ }^{\mathrm{b}} p=0.23$, Pearson's Chi-squared test

difference in cell counts between the two methods was significantly different from $0(P<0.001)$, tested using Wilcoxon signed rank test.

Evaluating the cellularity obtained by self-collection performed by the two subgroups of study participants (health professionals/women attending screening), no difference was observed $(P=0.19)$.

\section{Discussion}

Main findings

Our study showed fair concordance in HPV detection between the paired self-collected and clinician-collected samples, with no statistically significant differences between the two procedures. Both sampling methods provided material of sufficient quality and cellularity for molecular diagnostics. The self-collecting procedure was well accepted among study participants.

\section{Methodology and results}

Overall, enabling women to perform self-collection of samples is an important avenue in facilitating greater coverage and participance in cervical cancer screening programs. Self-sampling is considered to improve the subjective patient experience, increase screening coverage, and ultimately reduce morbidity and mortality related to HPV infection and cervical cancer [22]. In Mexico, cervical cancer is still a major public health problem. An infrastructure is in place for national cervical cancer prevention and early detection programs in most Mexican states, but organization is inefficient and implementation is poor [23]. This was an essential motive for conducting this study among the Mexican population. With evidence to support the performance of the self-sampling method it can be possible to justify implementing this method in national screening programs, enabling women to receive and send samples remotely, without the need to visit a clinic which can be an obstacle to participation, thus increasing coverage and participation numbers to further decreasing figures for mortality and incidence of cervical cancer.

As in every difficult to reach population, there is a considerable risk of loss to follow-up as a consequence of inadequate self-collected samples or the need of a clinician-collected sample for triage purposes. Some studies reflect the importance of sample quality and number of samples to be rejected due to low cellularity. In this study, all paired samples had sufficient sample material allowing two individual molecular tests to be done, with no need for revisits due to invalid test results. Since both tests provide qualitative results with no accurate quantification of pathogen load, the influence caused by the observed higher cellularity per milliliter in self-collected sample aliquot for HPV-testing needs to be interpreted with caution. Cut-off values for HPV positivity established by manufacturer $(\mathrm{CT}<32.0)$ is designed to optimize clinical performance, and since no relevant clinical outcome by the means of cytology or histology is available in this study, this will not be possible to discuss. It is well known that PAP test sensitivity [24] varies dramatically, highly impacted by sampling technique [25] emphasizing the importance of an optimal combination of sampling techniques to increase

Table 6 Descriptive statistics for cellularity (number of cells $/ \mathrm{mL}$ )

\begin{tabular}{|c|c|c|c|c|c|c|c|}
\hline Sample & $\mathrm{N}$ & Min. & Max. & Mean & Median & 1st Qu. & 3rd Qu. \\
\hline Clinician-collected & 97 & 13,333 & $6,880,000$ & 630,653 & 293,333 & 146,667 & 546,667 \\
\hline Self-collected ${ }^{a}$ & 97 & 13,333 & $10,866,667$ & $1,866,804$ & $1,600,000$ & 773,333 & $2,733,333$ \\
\hline -SC (health prof.) ${ }^{b}$ & 47 & 93,333 & $5,733,333$ & $1,647,943$ & $1,266,667$ & 653,333 & $2,560,000$ \\
\hline -SC (attn scr. $)^{b}$ & 50 & 13,333 & $10,866,667$ & $2,072,533$ & $1,906,667$ & 980,000 & $2,753,333$ \\
\hline Valid N (listwise) & 97 & & & & & & \\
\hline
\end{tabular}

a Self-collected samples had significantly higher cellularity than Clinician-collected samples $(P<0.001)$

${ }^{\mathrm{b}}$ Self-collected samples by health professionals had similar cellularity to self-collected samples by women attending screening $(P=0.19)$ 
screening participation with a highly specific molecular triage strategy to manage the positive results following HPV testing.

Within this study population, the hr-HPV detection rate by PCR assay was about $20 \%$, which is comparable to the prevalence $(24.7 \%)$ found in another study conducted in the Mexican population [26]. Clinical relevance caused by detecting vaginal HPV is not possible to conclude in our study set-up, in the absence of corresponding histology results. However, previous research shows that HPV is present beyond the transformation zone and the consequence of HPV infection differs depending on the site of infection in the cervix [27]. Both sampling techniques were performed upon the same visit, with the likelihood to collect infected cells by the first sampling method resulting in insufficient cell material for next sample procedure to reproduce HPV positivity. However, our results showed that the order of sampling was found not to be statistically significant for any discordant HPV result.

The obtained significant higher cellularity per milliliter for the self-collected versus the clinician-collected specimens in this study might be explained by the fact that XytoTest has an area coated with a highly adhesive hypoallergenic elastomer and therefore cells are more readily collected as soon as the device is inserted into the vagina.

\section{Perspectives}

It is known that molecular biomarkers are of vital importance in relation to the triage of patients in cervical screening programmes [28]. All current screening programs that utilize HPV-testing rely on cytology for triaging positive samples prior to referral for colposcopy. However, cytology is subjective in nature and the widespread implementation of this practice leads to over-referral, particularly for low-grade cellular abnormalities, which continues to be challenging from the clinical perspective [29].

The perspective of implementing HPV mRNA in triage of test positives are among one of the options discussed to represent an improved, highly specific riskbased approach for maximizing screening benefits and minimizing harms [19-21, 30].

Our data confirm 7-type mRNA testing to be applicable for reflex testing on self-collected specimens. Among the study participants, only one third of the HPV infected women had a positive mRNA test, an appealing situation for effective triage reducing the number of colposcopies and biopsies.

Recent research has proven the 7 genotypes included in the mRNA test to be the most important to screen for, being responsible for $90 \%$ of all cervical cancers [29, 31, 32].
Reliable self-sampling methods and molecular diagnostics may significantly aid prevention of cervical cancer, by simplicity, increased accessibility to screening and accurate diagnostics.

By combining HPV-DNA testing and identification of mRNA E6/E7 biomarkers, both high sensitivity and specificity might be maintained for improved patient management [33, 34].

\section{Limitations}

A clear limitation of this study is the lack of clinical data; cytology and a histology examination of samples that were found to be hr-HPV positive or mRNA E6/E7 positive, which would have enabled associations to be drawn between molecular assays with possible morphological changes, and presumably identify progression of cervical lesions. Unfortunately, these data were not available for our review, nor contemplated in the inclusion criteria of this study.

Although the acceptability of self-collected samples was found to be high among the women participating in this study, the questionnaires are of limited reliability because the study administered no parallel healthcare provider-reported questionnaire.

\section{Conclusions}

This comparative study of two sampling methods reports fair agreement of hr-HPV positivity rates between the self-collected and clinician-collected specimens using Abbott hr-HPV and PreTect HPV-Proofer'7 tests. Only one third of HPV-DNA positive women had overexpression of mRNA E6/E7, effectively discriminating women warranted for immediate colposcopy/biopsy from return to follow-up and suggests longer follow-up interval for single HPV-DNA positive women. Such a strategy will inevitably reduce over-referral for colposcopy but needs clinical and cost-benefit assessment in prospective studies.

\section{Supplementary Information}

The online version contains supplementary material available at https://doi. org/10.1186/s12879-021-06189-2.

\section{Additional file 1.}

\section{Acknowledgements}

The authors would like to thank all the study participants for volunteering and completing the questionnaire, enabling this study. We would like to extend our gratitude to the staff at the department of Oncoly-Ginecology \& department of Colposcopy, from General Hospital of Mexico "Eduardo Liceaga", and to all the laboratory staff performing HPV-testing for their great work and collaboration during this study.

Authors' contributions

CEAF conceptualized and designed the protocol. DCR, GGG, JMOL and CEAF took part in sample collection and informing study participants of test results and follow up. SWS reviewed HPV data and statistics, conducted literature 
review and citations. CEAF and SWS drafted the manuscript. All authors contributed to the critical review, read, and approved the final manuscript.

\section{Funding}

This study was partially funded by the General Hospital of Mexico. Abbott Laboratories, Division of scientific global affairs, US donated the HPV-DNA reagents to complete the study. PreTect AS, Norway, provided HPV mRNA kits at reduced research cost. In addition, Mel- Mont Medical, US, the manufacturer of the XytoTest device, provided the self-collection device and all necessary consumables for the study. The funding body had no role in the design of the study and collection, analysis, and interpretation of data or in writing the manuscript.

\section{Availability of data and materials}

The dataset used in this study contains personal information and is not publicly available, however an anonymized dataset is available from the corresponding author on reasonable request.

\section{Declarations}

\section{Ethics approval and consent to participate}

The study was approved by the institutional ethics review board at Eduardo Liceaga, Mexico General Hospital, Mexico City. Reference no: Cl/243/18. A signed written consent was in place for all study participants prior to enrollment.

\section{Consent for publication}

Not applicable.

\section{Competing interests}

None of the authors were compensated for their work, nor have any shares in any of the manufacturers companies or have been receiving bonuses from any related party. The authors declare that they have no competing interests.

\section{Author details}

'Oncology Department, Hospital General de México "Eduardo Liceaga", Mexico City, Mexico. ${ }^{2}$ Department of Colposcopy, Hospital General de Mexico "Eduardo Liceaga", Mexico City, Mexico. ${ }^{3}$ Oncoly-Ginecology Department (R5), Hospital General de Mexico "Eduardo Liceaga", Mexico City, Mexico. ${ }^{4}$ Department of Clinical Pathology, University Hospital of North Norway, Tromsø, Norway.

\section{Received: 2 February 2021 Accepted: 16 May 2021}

Published online: 31 May 2021

\section{References}

1. WHO. Human papillomavirus (HPV) and cervical cancer. 2020. https://www who.int/news-room/fact-sheets/detail/human-papillomavirus-(hpv)-andcervical-cancer. Accessed 15 Dec 2020.

2. Arbyn $M$, Castellsague $X$, de Sanjose $S$, Bruni $L$, Saraiya M, Bray F, et al. Worldwide burden of cervical cancer in 2008. Ann Oncol. 2011;22(12):267586. https://doi.org/10.1093/annonc/mdr015.

3. Walboomers JM, Jacobs MV, Manos MM, Bosch FX, Kummer JA, Shah KV, et al. Human papillomavirus is a necessary cause of invasive cervical cancer worldwide. J Pathol. 1999;189(1):12-9. https://doi.org/10.1002/(SICI)10969896(199909) 189:1<12::AID-PATH431>3.0.CO;2-F.

4. Arbyn M, Ronco G, Anttila A, Meijer CJ, Poljak M, Ogilvie G, et al. Evidence regarding human papillomavirus testing in secondary prevention of cervical cancer. Vaccine. 2012;30(Suppl 5):F88-99. https://doi.org/10.1016/j.vaccine.2 012.06.095.

5. Cuzick J, Arbyn M, Sankaranarayanan R, Tsu V, Ronco G, Mayrand MH, et al. Overview of human papillomavirus-based and other novel options for cervical cancer screening in developed and developing countries. Vaccine. 2008;26(Suppl 10):K29-41. https://doi.org/10.1016/j.vaccine.2008.06.019.

6. IARC Working Group on the Evaluation of Carcinogenic Risks to Humans. Human papillomaviruses. IARC Monogr Eval Carcinog Risks Hum. 2007;90:1636.

7. Sultana F, Mullins R, English DR, Simpson JA, Drennan KT, Heley S, et al. Women's experience with home-based self-sampling for human papillomavirus testing. BMC Cancer. 2015;15(1):849. https://doi.org/10.1186/ s12885-015-1804-x.

8. Mariño $H$, Serra E, Gutiérrez A. Self-sampling is as much effective as gynecologist samples for HPV detection. Medicina Balear. 2015;30:16-20.

9. Petignat P, Faltin DL, Bruchim I, Tramer MR, Franco EL, Coutlee F. Are selfcollected samples comparable to physician-collected cervical specimens for human papillomavirus DNA testing? A systematic review and meta-analysis. Gynecol Oncol. 2007;105(2):530-5. https://doi.org/10.1016/j.ygyno.2007.01. 023.

10. Schmeink CE, Bekkers RL, Massuger LF, Melchers WJ. The potential role of self-sampling for high-risk human papillomavirus detection in cervical cancer screening. Rev Med Virol. 2011;21(3):139-53. https://doi.org/10.1002/ rmv.686.

11. Arbyn M, Verdoodt F, Snijders PJ, Verhoef VM, Suonio E, Dillner L, et al. Accuracy of human papillomavirus testing on self-collected versus cliniciancollected samples: a meta-analysis. Lancet Oncol. 2014;15(2):172-83. https:// doi.org/10.1016/S1470-2045(13)70570-9.

12. Verhoef VM, Bosgraaf RP, van Kemenade FJ, Rozendaal L, Heideman DA, Hesselink AT, et al. Triage by methylation-marker testing versus cytology in women who test HPV-positive on self-collected cervicovaginal specimens (PROHTECT-3): a randomised controlled non-inferiority trial. Lancet Oncol. 2014;15(3):315-22. https://doi.org/10.1016/S1470-2045(14)70019-1.

13. Leinonen MK, Schee K, Jonassen CM, Lie AK, Nystrand CF, Rangberg A, et al. Safety and acceptability of human papillomavirus testing of self-collected specimens: A methodologic study of the impact of collection devices and HPV assays on sensitivity for cervical cancer and high-grade lesions. J Clin Virol. 2018;99-100:22-30.

14. Mel-Mont Medical. Xytotest, prevencion en tus propias manos del VPH. 2020. https://www.mel-montmedical.net/nuestro-dispositivo. Accessed 15 Dec 2020.

15. Rovers. Cervex-Brush. 2020. https://www.roversmedicaldevices.com/cell-sa mpling-devices/cervex-brush/. Accessed 15 Dec 2020.

16. Neubauer. Manual Cell Counting With Neubauer Chamber. 2020. https:// www.bio-rad.com/en-no/category/cell-counting. Accessed 15 Dec 2020.

17. Jentschke $M$, Soergel $P$, Hillemanns P. Evaluation of a multiplex real time PCR assay for the detection of human papillomavirus infections on selfcollected cervicovaginal lavage samples. J Virol Methods. 2013 Oct;193(1): 131-4. https://doi.org/10.1016/j.jviromet.2013.05.009.

18. Ko K, Yu S, Lee EH, Park H, Woo HY, Kwon MJ. Comparison of Abbott RealTime high-risk HPV and hybrid capture 2 assays for detection of HPV infection. Ann Clin Lab Sci. 2016;46(5):522-8.

19. Sorbye SW, Fismen S, Gutteberg TJ, Mortensen ES, Skjeldestad FE. HPV mRNA is more specific than HPV DNA in triage of women with minor cervical lesions. PLoS One. 2014;9(11):e112934. https://doi.org/10.1371/ journal.pone.0112934.

20. St-Martin G, Thamsborg LH, Andersen B, Christensen J, Ejersbo D, Jochumsen $\mathrm{K}$, et al. Management of low-grade cervical cytology in young women. Cohort study from Denmark. Acta Oncol. 2020;8:1-8.

21. Westre B, Giske A, Guttormsen H, Sorbye SW, Skjeldestad FE. 5-type HPV mRNA versus 14-type HPV DNA test: test performance, over-diagnosis and overtreatment in triage of women with minor cervical lesions. BMC Clin Pathol. 2016;16(1):9. https://doi.org/10.1186/s12907-016-0032-x.

22. Gupta S, Palmer C, Bik EM, Cardenas JP, Nunez H, Kraal L, et al. SelfSampling for Human Papillomavirus Testing: Increased Cervical Cancer Screening Participation and Incorporation in International Screening Programs. Front Public Health. 2018;6:77. https://doi.org/10.3389/fpubh.2018. 00077.

23. Gaceta Mexicana de Oncologia. Primer consenso nacional de prevención, diagnóstico y tratamiento del cáncer cervicouterino. 2014. https://www.ga mo-smeo.com/temp/SUPLE\%204\%20CANCER\%20CERVICOUTERINO.PDF. Accessed 15 Dec 2020.

24. Sorbye SW, Suhrke P, Reva BW, Berland J, Maurseth RJ, Al-Shibli K. Accuracy of cervical cytology: comparison of diagnoses of 100 pap smears read by four pathologists at three hospitals in Norway. BMC Clin Pathol. 2017;17(1): 18. https://doi.org/10.1186/s12907-017-0058-8.

25. Mangold BR. Self-collected samples in cervical Cancer screening: results of HPV and pap self-collected samples compared to physician-obtained specimens. Acta Cytol. 2019;63(5):379-84. https://doi.org/10.1159/000499373.

26. Campos-Romero A, Anderson KS, Longatto-Filho A, Luna-Ruiz Esparza MA, Moran-Portela DJ, Castro-Menendez JA, et al. The burden of 14 hr-HPV genotypes in women attending routine cervical cancer screening in 20 
states of Mexico: a cross-sectional study. Sci Rep. 2019;9(1):10094. https:// doi.org/10.1038/s41598-019-46543-8.

27. Doorbar J, Griffin H. Refining our understanding of cervical neoplasia and its cellular origins. Papillomavirus Res. 2019;7:176-9. https://doi.org/10.1016/j. pvr.2019.04.005.

28. Bonde J, Floore A, Ejegod D, Vink FJ, Hesselink A, van de Ven PM, et al. Methylation markers FAM19A4 and miR124-2 as triage strategy for primary human papillomavirus screen positive women: a large European multicenter study. Int J Cancer. 2021;148(2):396-405. https://doi.org/10.1002/ijc.33320.

29. Bonde JH, Sandri MT, Gary DS, Andrews JC. Clinical utility of human papillomavirus genotyping in cervical Cancer screening: a systematic review. J Low Genit Tract Dis. 2020;24(1):1-13. https://doi.org/10.1097/LGT. 0000000000000494.

30. Benevolo M, Vocaturo A, Caraceni D, French D, Rosini S, Zappacosta R, et al. Sensitivity, specificity, and clinical value of human papillomavirus (HPV) E6/ E7 mRNA assay as a triage test for cervical cytology and HPV DNA test. J Clin Microbiol. 2011;49(7):2643-50. https://doi.org/10.1128/JCM.02570-10

31. Arbyn M, Tommasino M, Depuydt C, Dillner J. Are 20 human papillomavirus types causing cervical cancer? J Pathol. 2014;234(4):431-5. https://doi.org/1 0.1002/path.4424.

32. Sundström $K$, Dillner J. How Many Human Papillomavirus Types Do We Need to Screen For? J Infect Dis. 2021;223(9):1510-11. https://doi.org/10.1 093/infdis/jiaa587.

33. Hawkes D, Keung MHT, Huang Y, McDermott TL, Romano J, Saville M, et al. Self-collection for cervical screening programs: from research to reality. Cancers (Basel). 2020;12(4):1053.

34. Origoni M, Cristoforoni P, Carminati G, Stefani C, Costa S, Sandri MT, et al. E6/E7 mRNA testing for human papilloma virus-induced high-grade cervical intraepithelial disease (CIN2/CIN3): a promising perspective. Ecancermedicalscience. 2015;9:533.

\section{Publisher's Note}

Springer Nature remains neutral with regard to jurisdictional claims in published maps and institutional affiliations.

Ready to submit your research? Choose BMC and benefit from:

- fast, convenient online submission

- thorough peer review by experienced researchers in your field

- rapid publication on acceptance

- support for research data, including large and complex data types

- gold Open Access which fosters wider collaboration and increased citations

- maximum visibility for your research: over $100 \mathrm{M}$ website views per year

At $\mathrm{BMC}$, research is always in progress.

Learn more biomedcentral.com/submissions 